\title{
Open Forum
}

\section{Where are the limits to reconstruction?}

\author{
JONATHANE. ADLER Brooklyn College, CUNY
}

Can something be an argumentcontain premises and conclusion; aim at persuasion, etc. (fill in your favorite standard account) - but yet not best be represented in reconstructed (standardized) form, even for the purposes of capturing its rational persuasive force? A good example is Robert Herrick's "To the Virgins to Make Much of Time." The first stanza should prick the memory and give the flavor of Herrick's argument:

Gather ye rosebuds while ye may

Old Time is still a-flying;

And this same flower that smiles

to-day,

To-morrow will be dying.

Now I won't bother laying out the standardized argument. I assume it's fairly obvious, and all I want agreement on it that the result will lack the spirit of the original. It will be blunt, flatfooted, and unattractive. I suppose that if we flesh out the assumptions, the standardized argument will be valid, but of questionable soundness.

I also want to take the poem in an unsophisticated way. I want to avoid the questions of interpretation that are the stuff of heavy-duty literary criticism. For example, I assume that there is no special sort of meaning called poetic meaning-metaphors in poetry are to be understood within an account of metaphor generally. Finally, I follow a not especially attractive part of our tradition in ripping the poem out of the context in which Herrick wrote. These presuppositions are made in a preliminary way. Perhaps we will have cause to rethink them later.

So the poem as standardized fits all the definitions of argument that I know. But the result of applying the usual methods for standardization leaves us with something dead. (I'm sure I tried this kind of argument as a teen-ager-since 1 tried just about everything else-but it never seemed to work. Maybe I should have tried poet$r y$ ? Here is a case in which passion came to be the slave of (other's) reason.) Should we say that the argument as reconstructed captures all the cognitive force of the poem, whereas the life or the point of the poem goes beyond an attempt at establishing the truth of a preposition? And if we do so answer, does that signal a general thesis that all rational persuasion in extended writing is to be viewed (can usefully be viewed) as argument? If we do, I think it must be because we assume that whatever cognitive force a bit of reasoning has is a force that extends only to what can be explicitly captured in statements. This would mean that implicit or tacit (using Polanyi's term) persuasive power cannot be evaluated cognitively and hence is perhaps deceptive. This would apply, for example, to allusions. 
You might in this regard consider how to answer the one-in-every-class problem. A teacher painstakingly works through a difficult poem with her class. (The same point can be made for the teaching of some hard passage in philosophy.) She does a good job, and at the end there is illumination. But then one-kid-in-every-class will raise her hand to say: "Teacher, if that's what the poet (philosopher) meant, why didn't she just say so?"

I'm not raising this as a puzzle or as a rhetorical question. I think what it really concerns is how we understand the distinction between the force of words and the force of argument. We all know that often when we reconstruct an argument, the result is something incredibly heavy-handed compared to the readability of the original piece. My question is this: are we losing anything other than style by this reconstruction? Could there be something rational or cognitive that is also lost? If one reads a rigorous analytic philosopher like the late James Cornman, does his difficult method of rendering the reasoning of others into explicit premises and conclusion lose anything of substance? Is Cornman's method an ideal which we all would do well to approximate, problems of ability, rhetorical style, and costs of effort aside?

I recognize that my query conflates a number of questions concerning the relationship of readable language to the language of standardized arguments. But to separate the questions seems to require more progress towards answering them than I am presently ablt to muster. So I hope others, by clarifying my questions, will cast light on the answers.

Jonathan E. Adler, Department of Philosophy, Brooklyn College, CUNY, Brooklyn, NY 11210 